\title{
Excitotoxic glutamate causes neuronal insulin resistance by inhibiting insulin receptor/Akt/mTOR pathway
}

\author{
Igor Pomytkin ${ }^{1,2^{*}} \mathbb{D}$, Irina Krasil'nikova ${ }^{3}, Z^{2}$ anda Bakaeva ${ }^{3}$, Alexander Surin ${ }^{3,4}$ and Vsevolod Pinelis ${ }^{3}$
}

\begin{abstract}
Aim: An impaired biological response to insulin in the brain, known as central insulin resistance, was identified during stroke and traumatic brain injury, for which glutamate excitotoxicity is a common pathogenic factor. The exact molecular link between excitotoxicity and central insulin resistance remains unclear. To explore this issue, the present study aimed to investigate the effects of glutamate-evoked increases in intracellular free $\mathrm{Ca}^{2+}$ concentrations $\left[\mathrm{Ca}^{2+}\right]_{i}$ and mitochondrial depolarisations, two key factors associated with excitotoxicity, on the insulin-induced activation of the insulin receptor (IR) and components of the Akt/ mammalian target of rapamycin (mTOR) pathway in primary cultures of rat cortical neurons.

Methods: Changes in $\left[\mathrm{Ca}^{2+}\right]_{i}$ and mitochondrial inner membrane potentials $\left(\Delta \psi_{\mathrm{m}}\right)$ were monitored in rat cultured cortical neurons, using the fluorescent indicators Fura-FF and Rhodamine 123, respectively. The levels of active, phosphorylated signalling molecules associated with the IR/Akt/mTOR pathway were measured with the multiplex fluorescent immunoassay.

Results: When significant mitochondrial depolarisations occurred due to glutamate-evoked massive influxes of $\mathrm{Ca}^{2+}$ into the cells, insulin induced 48\% less activation of the IR (assessed by IR tyrosine phosphorylation, $\mathrm{pY}^{1150 / 1151}$ ), $72 \%$ less activation of Akt (assessed by Akt serine phosphorylation, $\mathrm{ps}^{473}$ ), 44\% less activation of mTOR (assessed by mTOR $\mathrm{ps}^{2448}$ ), and 38\% less inhibition of glycogen synthase kinase $\beta$ (GSK3 $\beta$ ) (assessed by GSK3 $\beta$ pS ${ }^{9}$ ) compared with respective controls. These results suggested that excitotoxic glutamate inhibits signalling via the IR/Akt/mTOR pathway at multiple levels, including the IR, resulting in the development of acute neuronal insulin resistance within minutes, as an early pathological event associated with excitotoxicity.
\end{abstract}

Keywords: Insulin, Glutamate excitotoxicity, Central insulin resistance

\section{Main text}

An acute impairment in the biological response to insulin in the brain, known as central insulin resistance, was identified during stroke [1] and traumatic brain injury [2], for which excitotoxicity, which is caused by excessive glutamate release, is a key pathogenic factor [3].

The exact molecular link between insulin resistance and glutamate excitotoxicity remains unclear. Based on published data, an abnormal rise in intracellular free

\footnotetext{
* Correspondence: ipomytkin@mail.ru

${ }^{1}$ Institute of Regenerative Medicine, I.M. Sechenov First Moscow State

Medical University, Trubetskaya Street, 8, 119991 Moscow, Russia

${ }^{2}$ Scientific Center for Biomedical Technologies, Federal Medical and

Biological Agency, 143442 Svetlye Gory, Moscow region, Russia

Full list of author information is available at the end of the article
}

$\mathrm{Ca}^{2+}$ concentration $\left(\left[\mathrm{Ca}^{2+}\right]_{\mathrm{i}}\right)$ and decreased mitochondrial inner membrane potential $\left(\Delta \Psi_{\mathrm{m}}\right)$ are factors associated with the excitotoxic glutamate [4-6], which could potentially affect insulin signalling. The presence of $\mathrm{Ca}^{2+}$ $(1 \mathrm{mM})$ has been shown to reduce the insulin-induced tyrosine phosphorylation of the insulin receptor (IR) in hippocampal synaptic preparations [7]. Glutamate has been shown to reduce the tyrosine phosphorylation of the IR when added after the prolonged insulin-mediated stimulation of hippocampal neuronal cultures [8]. Protonophore-induced decreases in $\Delta \Psi_{\mathrm{m}}$ have been shown to evoke concomitant decreases in the IR tyrosine phosphorylation in response to insulin, indicating that mitochondrial depolarisation is an independent causative factor for neuronal insulin resistance [9]. However, the 
effects of glutamate-evoked changes in $\left[\mathrm{Ca}^{2+}\right]_{\mathrm{i}}$ and $\Delta \Psi_{\mathrm{m}}$ on the insulin-induced activation of the IR/Akt/mammalian target of rapamycin (mTOR) and glycogen synthase kinase (GSK) $3 \beta$ pathways have never been studied. Here, we investigated whether excitotoxic glutamate affects the insulin-induced phosphorylation of IR/Akt/mTOR pathway components during significant mitochondrial depolarisations caused by the massive influx of $\mathrm{Ca}^{2+}$ into the cells.

To determine the times during which glutamate induces significant mitochondrial depolarisation, rat cortical neurons were exposed to $100 \mu \mathrm{M}$ glutamate and changes in $\left[\mathrm{Ca}^{2+}\right]_{\mathrm{i}}$, and $\Delta \Psi_{\mathrm{m}}$ were monitored for $30 \mathrm{~min}$. Detailed methods for the preparation of primary cortical neuronal cultures and measuring $\left[\mathrm{Ca}^{2+}\right]_{\mathrm{i}}$ and $\Delta \Psi_{\mathrm{m}}$ are described in Additional file 1. As expected, glutamate evoked a rapid increase in $\left[\mathrm{Ca}^{2+}\right]_{\mathrm{i}}$, followed by a decreased in $\Delta \Psi_{\mathrm{m}}$ in the cells (Fig. 1a and b, Additional file 2: Tables S3 and S4). After $30 \mathrm{~min}$ of glutamate exposure, the mean $\left[\mathrm{Ca}^{2+}\right]_{\mathrm{i}}$ level increased by 2.4 -fold above baseline $\left(\mathrm{F}_{148,8732}=44.8, P<0.0001\right)$, and the mean $\Delta \Psi_{\mathrm{m}}$ value significantly decreased by 1.6 -fold below baseline $\left(\mathrm{F}_{148,8732}=182.8, P<0.0001\right)($ Fig. 1a-c, one-way analysis of variance $[\mathrm{ANOVA}]$ with repeated measures, followed
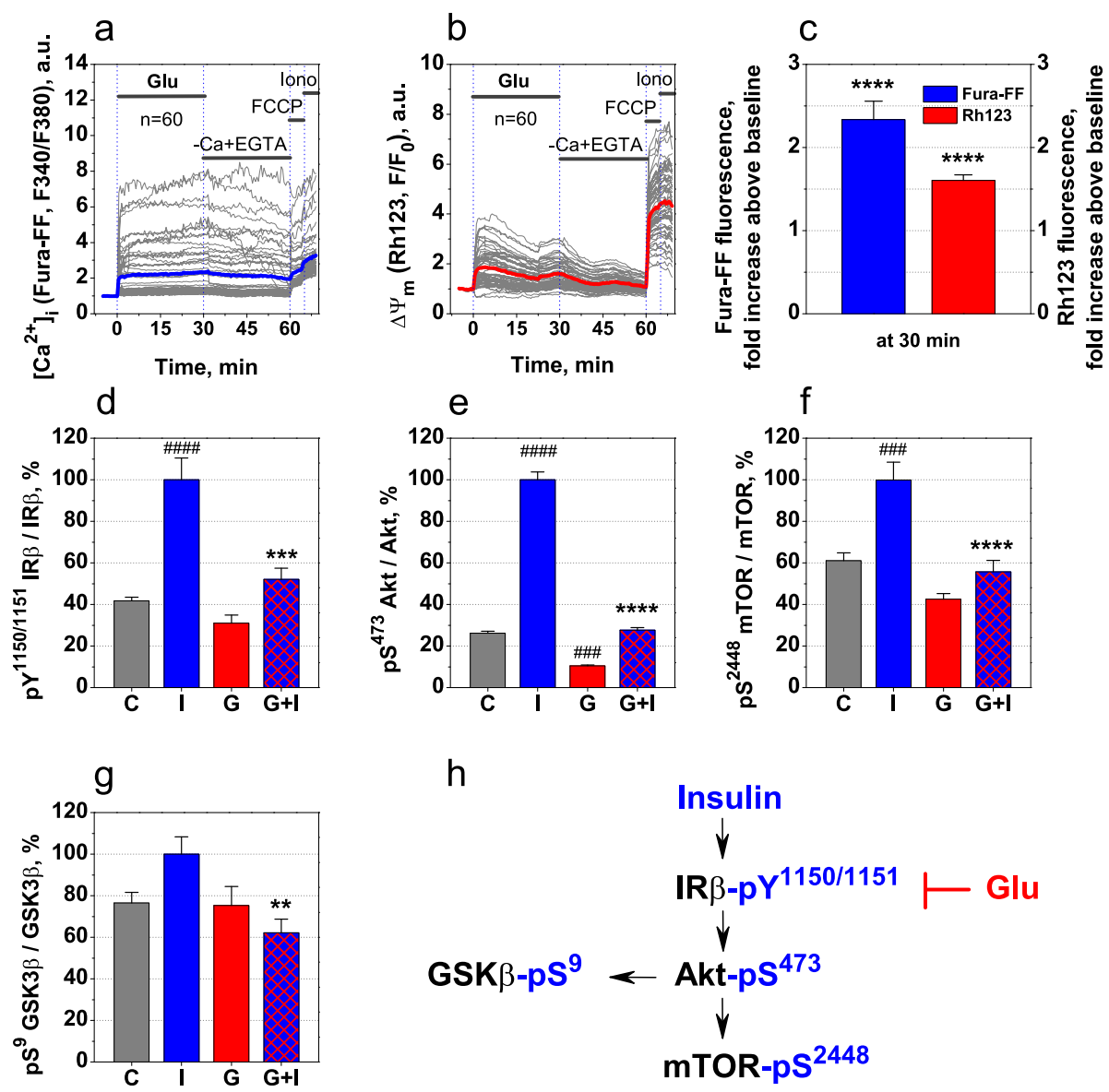

Fig. 1 Excitotoxic glutamate inhibits IR/Akt/mTOR pathwaya Dynamics of $\left[\mathrm{Ca}^{2+}\right]_{\mathrm{i}}$ and $\mathbf{b} \Delta \psi_{\mathrm{m}}$ in single rat cortical neurons, loaded simultaneously with Fura-FF and Rh123 dyes and exposed to $100 \mu \mathrm{M}$ glutamate. Grey lines represent sixty single neurons. Blue and red lines represent the respective means of $\left[\mathrm{Ca}^{2+}\right]_{i}$ and $\Delta \psi_{\mathrm{m}}$, averaged across sixty individual neurons at every time point. c Fura-FF and Rh123 fluorescence $30 \mathrm{~min}$ after the onset of glutamate exposure, expressed as the fold increase over baseline (at $-5 \mathrm{~min}$ ). Data are the mean \pm SEM from sixty neurons. ${ }^{* * *} P<0.0001$ compared to respective baselines (one-way ANOVA with repeated measures, followed by Tukey's post hoc test). $\mathbf{d}-\mathbf{g}$ Levels of $\mathbf{d} I R \beta \mathrm{pY}^{1150 / 1151}$, e $A k t \mathrm{pS}^{473}, \mathbf{f} \mathrm{mTOR}_{\mathrm{pS}} \mathrm{S}^{2448}$, and $\mathbf{g} \mathrm{GSK3} \beta \mathrm{pS}^{9}$ in rat cortical neurons exposed to $0 \mathrm{nM}$ (C) or $100 \mathrm{nM}$ insulin for $15 \mathrm{~min}(\mathrm{I}), 100 \mu \mathrm{M}$ glutamate for $30 \mathrm{~min} \mathbf{g}$, or sequentially to $100 \mu \mathrm{M}$ glutamate for $30 \mathrm{~min}$ and $100 \mathrm{nM}$ insulin for $15 \mathrm{~min}(\mathrm{G}+\mathrm{I})$. Bar graphs represent the levels of the phosphoproteins, normalised against respective total protein levels, in cell lysates and expressed as a percentage of levels in insulin-treated cells (group I). Each value represents the mean \pm SEM from six

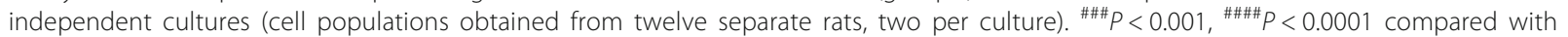
untreated control $\mathbf{c}_{;}{ }^{*} P<0.01,{ }^{* *} P<0.001,{ }^{* * *} P<0.0001$ compared with insulin $\mathbf{i}$ (one-way ANOVA, followed by Tukey's post hoc test for multiple comparisons). $\mathbf{h}$ Scheme illustrating the inhibitory effects of glutamate on the insulin-induced activation of the IR/Akt/mTOR pathway. 
by Tukey's post hoc test). Therefore, the 30 -min interval for glutamate exposure was selected for subsequent experiments.

Next, we investigated the effects of glutamate on the insulin-induced activation of signalling molecules in the IR/Akt/mTOR and GSK3 $\beta$ pathways. Rat cortical neuronal cultures were sequentially exposed to either $100 \mu \mathrm{M}$ excitotoxic glutamate concentration or no glutamate for $30 \mathrm{~min}$, then stimulated with $100 \mathrm{nM}$ insulin for $15 \mathrm{~min}$ and lysed. The levels of the tyrosinephosphorylated IR $\beta$-subunit (IR $\beta \mathrm{pY}^{1150 / 1151}$ ), the serine-phosphorylated Ser/Thr kinase Akt (Akt $\mathrm{pS}^{473}$ ), the serine-phosphorylated mammalian target of rapamycin (mTOR $\mathrm{pS}^{2448}$ ), and the serine-phosphorylated glycogen synthase kinase $3 \beta\left(\mathrm{GSK} 3 \beta \mathrm{pS}^{9}\right)$ were measured in the cell lysates and normalised against the total levels of these proteins, as outlined in Additional file 1. A oneway ANOVA analysis revealed a significant difference between groups for IR $\beta \mathrm{pY}^{1150 / 1151}$ (Fig. $1 \mathrm{~d}, \mathrm{~F}_{3,20}=23.62$, $P<0.0001$ ), Akt $\mathrm{pS}^{473}$ (Fig. 1e, $\mathrm{F}_{3,20}=388.6, P<0.0001$ ), mTOR pS $^{2448}$ (Fig. 1f, $F_{3,20}=19.69, P<0.0001$ ), and GSK3 $\beta$ pS $^{9}$ (Fig. 1g, $F_{3,20}=4.48, P=0.0146$ ). Tukey's multiple comparisons test showed that insulin stimulation resulted in a significant increase in $\operatorname{IR} \beta \mathrm{pY}^{1150 / 1151}$ (Fig. 1d, $P<0.0001$ ), Akt $\mathrm{pS}^{473}$ (Fig. 1e, $P<0.0001$ ), and mTOR $\mathrm{pS}^{2448}$ (Fig. 1f, $P<0.001$ ) levels compared with their respective controls (Additional file 1: Tables S1 and S2). In the glutamate pre-treated neurons, insulin induced $48 \%$ less IR phosphorylation at $\mathrm{pY}^{1150 / 1151}$ (Fig. 1d, $P<0.001), 72 \%$ less Akt phosphorylation at $\mathrm{pS}^{473}$ (Fig. 1e, $P<0.0001$ ), 44\% less mTOR phosphorylation at $\mathrm{pS}^{2448}$ (Fig. 1f, $P<0.0001$ ), and 38\% less GSK3 $\beta$ phosphorylation at $\mathrm{pS}^{9}$ (Fig. 1g, $P<0.01$ ) compared with nonglutamate treated controls. Neuronal IR becomes fully active following autophosphorylation at $\mathrm{Y}^{1150 / 1151}$ [10], which triggers downstream signalling via the Akt/mTOR and GSK3 $\beta$ pathways. The serine-phosphorylation of Akt at $S^{473}$ [11] and mTOR at $S^{2448}$ [12] are crucial for their activation, whereas the serine-phosphorylation of GSK3 $\beta$ at $S^{9}$ [13] leads to its inhibition. Therefore, our results suggested that excitotoxic glutamate inhibits insulininduced IR activation and the downstream IR/Akt/mTOR signalling pathway (Fig. 1h).

The primary finding of the present study was that excitotoxic glutamate inhibits the IR/Akt/mTOR pathway, resulting in the development of acute neuronal insulin resistance during periods of significant mitochondrial depolarisation caused by glutamate-evoked massive influxes of $\mathrm{Ca}^{2+}$. This rapid loss of neuronal insulin sensitivity appears to be one of the earliest pathological events associated with glutamate excitotoxicity. These results are in complete agreement with our previous findings that mitochondria control IR autophosphorylation in neurons and that mitochondrial depolarisation causes the loss of insulin sensitivity during the IR autophosphorylation stage [9, 14]. Recently we showed that pre-treatment with insulin prevents the glutamate-evoked increases in $\left[\mathrm{Ca}^{2+}\right]_{\mathrm{i}}$ and decreases in $\Delta \Psi_{\mathrm{m}}$, protecting rat cortical neurons against excitotoxicity [15]. The glutamate effect and the protective effects of insulin were both completely abrogated by MK 801, an inhibitor of $\mathrm{Ca}^{2+}$ influx, via the N-methyl-D-aspartate (NMDA) receptor and the plasmalemmal $\mathrm{Na}^{+} / \mathrm{Ca}^{2+}$ exchanger operating in reverse mode [15]. Collectively, these findings suggested that the modulation of intracellular $\mathrm{Ca}^{2+}$ levels plays a critical role in negative crosstalk between insulin and glutamate signalling during excitotoxicity. Glutamate induces an increase in $\left[\mathrm{Ca}^{2+}\right]_{\mathrm{i}}$ and a decrease in $\Delta \Psi_{\mathrm{m}}$, which inhibit IR activation. In turn, insulin prevents the glutamate-evoked rise in $\left[\mathrm{Ca}^{2+}\right]_{\mathrm{i}}$ and mitochondrial depolarisation, protecting against excitotoxicity.

In conclusion, this study showed that glutamate excitotoxicity is causative for central insulin resistance and may induce the acute loss of insulin signalling within minutes under mitochondrial depolarisation conditions. Therefore, the use of agents designed to prevent mitochondrial depolarisation may be a reasonable approach to the treatment of acute neuronal insulin resistance during excitotoxicity.

\section{Supplementary information}

Supplementary information accompanies this paper at https://doi.org/10. 1186/s13041-019-0533-5.

Additional file 1: Figure S1. Representative images of fluorescence staining of cell culture on (A) DAPI, (B) GFAP, (C) blllTubulin, and (D) Merge, scalebar $100 \mu \mathrm{m}$. (A), Table S1. Raw data of phosphoproteins measurements in cell lysates, Table S2. Results of statistical analysis.

Additional file 2: Table S3. Raw data of [Ca2+]i (Fura-FF f340/f380

fluorescence) measurements.

\section{Abbreviations}

$\left[\mathrm{Ca}^{2+}\right]_{\mathrm{i}}$ Intracellular free $\mathrm{Ca}^{2+}$ concentration; Akt: The Ser/Thr kinase Akt; ANOVA: analysis of variance; GSK3 $\beta$ : The glycogen synthase kinase $3 \beta$; IR: Insulin receptor; IR $\beta$ : Insulin receptor $\beta$-subunit; mTOR: The mammalian target of rapamycin; $\Delta \psi_{\mathrm{m}}$ : Mitochondrial inner membrane potential

\section{Acknowledgements}

Not applicable.

Authors' contributions

$I K, A S, V P$, and IP conceived and designed the experiments. IP wrote the article. IK and ZB performed experiments. IK, VP, and IP analyzed the data. All authors read and approved the final manuscript.

\section{Funding}

This work was supported by Russian Ministry of Health, the project N. AAAAA19-119012590191-3.

Availability of data and materials

All data are available in the Additional file 1 and Additional file 2. 


\section{Ethics approval and consent to participate}

Experiments with animals were performed in accordance with the ethical principles and regulatory documents recommended by the European Convention on the Protection of Vertebrate Animals used for experiments (Guide for the Animals and Eighth Edition. 2010), as well as in accordance with the "Good Laboratory Rules practice", approved by order of the Ministry of Health of the Russian Federation No. 199n of 04/01/2016. The experimental procedures were approved by the Ethics Committee at National Medical Research Center for Children's Health, Russian Ministry of Health.

\section{Consent for publication}

Not applicable.

\section{Competing interests}

The authors declare that they have no competing interests.

\section{Author details}

Institute of Regenerative Medicine, I.M. Sechenov First Moscow State Medical University, Trubetskaya Street, 8, 119991 Moscow, Russia. ${ }^{2}$ Scientific Center for Biomedical Technologies, Federal Medical and Biological Agency, 143442 Svetlye Gory, Moscow region, Russia. ${ }^{3}$ National Medical Research Center for Children's Health, Russian Ministry of Health, Lomonosov's prospect, 2, 119991 Moscow, Russia. ${ }^{4}$ The Institute of General Pathology and Pathophysiology, Baltiyskaya Street, 8, 125315 Moscow, Russia.

\section{Received: 14 August 2019 Accepted: 11 December 2019}

Published online: 19 December 2019

\section{References}

1. Lai TW, Zhang S, Wang YT. Excitotoxicity and stroke: identifying novel targets for neuroprotection. Prog Neurobiol. 2014;115:157-88.

2. Karelina K, Sarac B, Freeman LM, Gaier KR, Weil ZM. Traumatic brain injury and obesity induce persistent central insulin resistance. Eur J Neurosci. 2016; 43:1034-43.

3. Guerriero RM, Giza CC, Rotenberg A. Glutamate and GABA imbalance following traumatic brain injury. Curr Neurol Neurosci Rep. 2015:15:27.

4. Nicholls DG. Mitochondrial dysfunction and glutamate excitotoxicity studied in primary neuronal cultures. Curr Mol Med. 2004:4:149-77.

5. Abramov AY, Duchen MR. Mechanisms underlying the loss of mitochondrial membrane potential in glutamate excitotoxicity. Biochim Biophys Acta. 1777;2008:953-64.

6. Duchen MR, Surin A, Jacobson J. Imaging mitochondrial function in intact cells. Methods Enzymol. 2003;361:353-89.

7. Zhao W, Chen H, Xu H, Moore E, Meiri N, Quon MJ, Alkon DL. Brain insulin receptors and spatial memory. Correlated changes in gene expression, tyrosine phosphorylation, and signaling molecules in the hippocampus of water maze trained rats. J Biol Chem. 1999:274: 34893-902.

8. Zhao WQ, De Felice FG, Fernandez S, Chen H, Lambert MP, Quon MJ, et al. Amyloid beta oligomers induce impairment of neuronal insulin receptors. FASEB J. 2008;22:246-60.

9. Persiyantseva NA, Storozhevykh TP, Senilova YE, Gorbacheva LR, Pinelis VG, Pomytkin IA. Mitochondrial H2O2 as an enable signal for triggering autophosphorylation of insulin receptor in neurons. J Mol Signal. 2013;8:11.

10. White MF, Kahn CR. The insulin signaling system. J Biol Chem. 1994; 269:1-4.

11. Alessi DR, Andjelkovic M, Caudwell B, Cron P, Morrice N, Cohen P, et al. Mechanism of activation of protein kinase B by insulin and IGF-1. EMBO J. 1996;15:6541-51

12. Nave BT, Ouwens M, Withers DJ, Alessi DR, Shepherd PR. Mammalian target of rapamycin is a direct target for protein kinase $B$ : identification of a convergence point for opposing effects of insulin and amino-acid deficiency on protein translation. Biochem J. 1999;344: 427-31.

13. Cross DA, Alessi DR, Cohen P, Andjelkovich M, Hemmings BA. Inhibition of glycogen synthase kinase-3 by insulin mediated by protein kinase B. Nat. 1995;378:785-9.

14. Storozhevykh TP, Senilova YE, Persiyantseva NA, Pinelis VG, Pomytkin IA. Mitochondrial respiratory chain is involved in insulin-stimulated hydrogen peroxide production and plays an integral role in insulin receptor autophosphorylation in neurons. BMC Neurosci. 2007:8:84

15. Krasil'nikova I, Surin A, Sorokina E, Fisenko A, Boyarkin D, Balyasin M, Demchenko A, Pomytkin I, Pinelis V. Insulin protects cortical neurons against glutamate excitotoxicity. Front Neurosci. 2019;13:1027.

\section{Publisher's Note}

Springer Nature remains neutral with regard to jurisdictional claims in published maps and institutional affiliations.
Ready to submit your research? Choose BMC and benefit from:

- fast, convenient online submission

- thorough peer review by experienced researchers in your field

- rapid publication on acceptance

- support for research data, including large and complex data types

- gold Open Access which fosters wider collaboration and increased citations

- maximum visibility for your research: over $100 \mathrm{M}$ website views per year

At $\mathrm{BMC}$, research is always in progress.

Learn more biomedcentral.com/submissions 